EPJ Web of Conferences 54, 01001 (2013)

DOI: $10.1051 /$ epjconf/20135401001

(C) Owned by the authors, published by EDP Sciences - SIF, 2013

\title{
Energy and scientific communication
}

\author{
E. De SANCTiS \\ INFN - Frascati National Laboratories, 00044 Frascati, Italy
}

\begin{abstract}
Summary. - Energy communication is a paradigmatic case of scientific communication. It is particularly important today, when the world is confronted with a number of immediate, urgent problems. Science communication has become a real duty and a big challenge for scientists. It serves to create and foster a climate of reciprocal knowledge and trust between science and society, and to establish a good level of interest and enthusiasm for research. For an effective communication it is important to establish an open dialogue with the audience, and a close collaboration among scientists and science communicators. An international collaboration in energy communication is appropriate to better support international and interdisciplinary research and projects.
\end{abstract}

\section{1. - Introduction}

Like food, air and water, energy is essential to human existence. The well-being of people, industry and economy depends on safe, secure, sustainable and affordable energy. There is, then, nothing surprising about the fact that the issues of energy matter receive a constant and continuously increasing interest within the public.

Everybody knows about energy. It is mentioned in many commercial advertisements on television, whether it is a utility trying to convince people it is the cheapest and greenest provider of energy or a car company promoting the energy efficiency of its 
engines. Energy supply and use is now a matter of frequent reports, not only in trade journals but in the popular press.

However, this does not mean that common people correctly understand energy matters. Moreover, among them the awareness of various aspects of energy use and production remains low and the interest for science discoveries coexists with a widespread lack of a "critical knowledge". This often generates fear, mistrust, and also opposition towards many advanced technologies and innovations.

Awareness and understanding of scientific ideas and issues by the public at any level is required to increase its ability to sift the plausible from implausible and to make the right decision, if the world is to regulate carbon emission, control overpopulation or make the best use of advanced technologies. An uninformed public is very vulnerable to misleading ideas. Therefore, far greater efforts are needed to correctly inform people.

Energy communication is particularly important today, when the world is facing several demanding challenges: the search for a sustainable energy supply, the danger of overpopulation and famine, the mounting social and racial conflicts, and the environment and safety concerns.

In the following I will, first, examine the scientific communication, of which energy communication is a paradigmatic case, then briefly present the world energy scenario and, finally, illustrate the main features of an effective energy communication.

\section{2. - Scientific communication}

Science pervades our society, playing a major role in most aspects of our daily lives, both at home and at work. Industry and thus the prosperity of the developed countries depend on science and technology. Many public policy issues of national and international importance have scientific implications. Science also affects many personal decisions, from health and diet, to holidays and sport. Therefore, everybody needs some understanding of science, its accomplishments and its limitations. Many personal decisions would be helped by some understanding of the underlying science.

The great paradox of science today is that while it is a hegemonic culture-few others are able to change our way of living, producing, working and thinking so profoundly and quickly - science literacy remains low. Although there is a general awareness of the public in various aspects of science, much more could and must be done to bring the fundamental scientific ideas nearer to the intelligent layman.

It is important to recognize that science is not "common sense" and that misconceptions abound. Scientists are the first to benefit from greater public awareness on science and its processes. Lack of transparency breeds fear, whilst transparency breeds trust within the public. As written by Josh Billings, pen name of the American writer Henry Wheeler Shaw, "It is not what a man doesn't know that makes him a fool, but what he does know that is not so!" [1].

Science communication is a suitable tool to create and foster a climate of reciprocal knowledge and trust between science and society, and to establish a good level of interest and enthusiasm for research. It also serves to facilitate and accelerate the assimilation of 
the new - a process that would otherwise be excessively slow-, and so building bridges between what people know, or are willing to accept, and the new.

The scientific enterprise can only be sustainable and innovative if it is able to communicate with society closely and effectively, and with great continuity. If the public is uninformed or uninterested, students will not want to study science, scientists will lose grants for research and will be unable to influence the public and political opinion over issues around food and energy supply, global warming, use of nuclear power in a world worried about carbon, genetically modified crops, cell-phone radio waves, etc.

Science communication has, therefore, become a real duty and a big challenge for scientists.

Communication of science should tell what science is: a concerted human effort to search for a unified, rational view of nature, made through the observation of natural phenomena, and/or through experimentation that tries to simulate natural processes under controlled conditions.

In the colloquial speech the word science is usually used to mean one of three things, or a mixture of them. "Science means, sometimes, a special method of finding things out. Sometimes it means the body of knowledge arising from the things found out. It may also mean the new things you can do when you have found something out, or the actual doing of new things. This last field is usually called technology" [2].

The most obvious characteristic of science is its application, the fact that as a consequence of scientific knowledge one has a power to do things. The importance of science as a basis of technology is commonplace. The whole industrial revolution would almost have been impossible without the development of science. Today, it is difficult to find a single industry that does not make use of the results of atomic physics or modern chemistry. The possibilities of producing quantities of food adequate for the present large world population, and of controlling sickness are the result of the development of scientific means of production.

However, despite application is the most perceived characteristic of science, it is the less important one. The by far most valuable aspect of science is its contents, the things that have been found out, the knowledge that has been produced. The latter has a profound and seminal influence in shaping our way of thinking, and is an important part of our culture.

This basic essence of science is not stressed enough, if not at all, when communicating to the public. Often, scientists are urged to illustrate people the possible applications of their research and forget to tell them what science is. People should be made fully aware that science is primarily culture and that the first and the deepest motivation for the research work is not the aspiration for an application but the excitement of what is found out.

In addition, science communication should also foster the familiarity with the scientific method, its nature and limitation, and provide the layman with a basic understanding of the nature of the risks and uncertainty. In fact, even more than facts, science is a process by which we make our best efforts to understand what is going on in the universe, in the natural and social world, and in ourselves. To think scientifically one needs many 
tools: ideas about cause and effect, respect for evidence and logical coherence, curiosity and intellectual honesty, the willingness to create hypotheses which can be tested, the willingness to refine one's ideas in the face of evidence. These are the core skills of science and scientists.

The scientific method is based on the principle that observation is the judge of whether something is so or not. All other aspects and characteristics of science can be understood directly when one understands that observation is the ultimate and final judge of the truth of an idea.

Another thing that should not be forgotten when communicating science is its international aspect. Science is a truly human concern; its concepts and language are the same for all human beings. It transcends any cultural and political boundaries. Scientists understand each other immediately when they talk about their scientific problems; it is therefore easier for them to speak to each other on political or cultural questions and problems about which they may have divergent opinions. The scientific community serves as a bridge across boundaries, as a spearhead of international understanding.

As an example one can mention the CERN laboratory [3] in which 20 European member states, and many non-European countries collaborate successfully in running a most active center in the world for fundamental research. The original thirteen nations have created a working model of the United States of Europe as far as high-energy physics is concerned. It is significant that this laboratory has had very close ties with the laboratories in the eastern part European countries also during the Iron Curtain period, when states on either side of the Curtain developed their own international economic and military alliances.

Another example is the International Space Station (ISS), the habitable artificial satellite in low Earth orbit. It is a result of a close collaboration between USA and Russia (a cooperation inconceivable only twenty-five years ago), and the Space Agencies of Europe, Japan, and Canada; men and women from 15 countries have been working there since its establishment.

Science communication should also deal with the tremendous relevance of basic scientific research. This is often considered to be an unnecessary luxury by people, particularly today, when the economic and environmental crisis has produced a trend among the public away from basic science towards the application of science to immediate problems and technological shortcomings.

People should understand that fundamental science has a vital role to play in the today's competitive world. The scientist who devotes his/her time to the solution of the social and environmental problems does an important job. But so does his/her colleague who goes on in the pursuit of basic science. It is fundamental science that lays the long-term foundations for innovations and prosperity.

Science needs the space for curiosity and imagination. History teaches us that the knowledge acquired by basic science has always yielded a vast technical return, and that big jumps in human innovation come about mainly as a basic result of pure curiosity. People should be made conscious that innovation is the key to meeting many of today's development challenges, and that the primary force for innovation is fundamental 


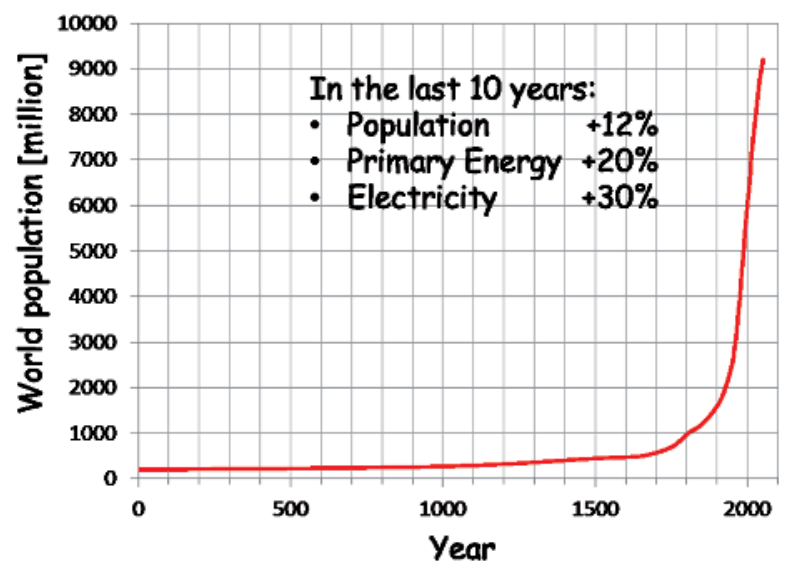

Fig. 1. - World population. (Source: OECD/IEA 2009.)

research. Without it, there would be no science to apply. Faraday's experiments on electricity, for example, were driven by curiosity but eventually brought us electric light. We would never have discovered electricity funding research to improve the burning efficiency of candles, and no amount of $\mathrm{R} \& \mathrm{D}$ on the telephone would have brought about the web.

\section{3. - Energy communication}

The biggest challenge facing energy communication is enabling people understand energy matters correctly.

A range of essential activities - including agriculture, manufacturing, construction, transport, computing, telecommunication, health and social services - depend on access to energy. In addition, many familiar elements of modern life would not exist without the plastics, chemicals and fertilizers made from oil and natural gas. The hopes of billions for a better life depend on plentiful and accessible sources of energy.

One of the central challenges of the 21st century is to ensure a sustainable energy supply for the world's people and their economy. But with the world's population over seven billion and fast approaching nine billion in 2050, how do we meet the growing demand for energy in a responsible, equitable, and sustainable way?

The striking unequal levels of energy consumption existing in the world energy system pose severe environmental and human challenges. It is interesting to focus the attention to some data.

Figure 1, constructed from data from ref. [4], illustrates how the world population has changed in history. At the dawn of agriculture, about $8000 \mathrm{BC}$, the population of the world was approximately 5 million. Over a 8000 -year period up to 1 AD it grew to about 200 million, with a growth rate of about $0.05 \%$ per year. A tremendous change occurred with the industrial revolution: whereas it had taken all of human history until around the year 1800 for world population to reach one billion, the second billion was 


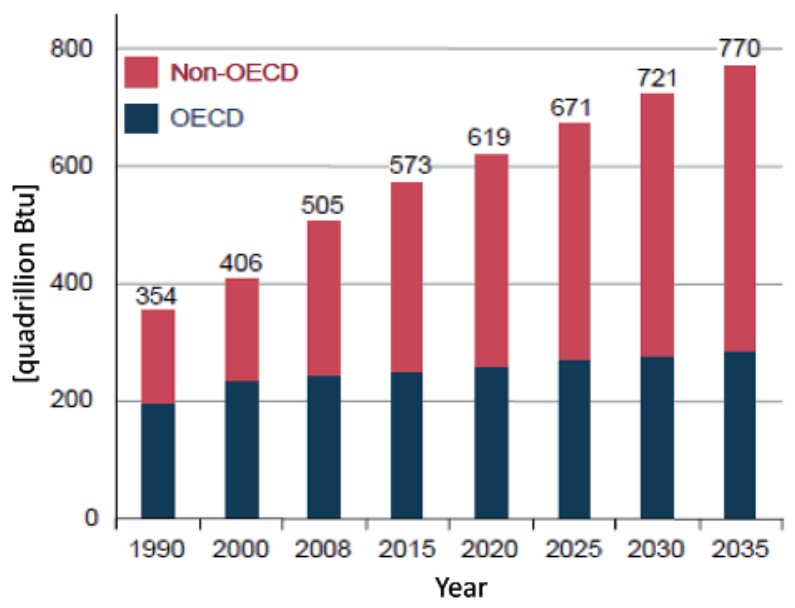

Fig. 2. - World energy consumption, in quadrillions of British thermal units (1 BTU $=1055.06 \mathrm{~J})$ in the years 1990-2035. (Source: OECD/IEA 2011.)

achieved in only 130 years (year 1930), the third billion in less than 30 years (year 1959), the fourth billion in 15 years (year 1974) and the fifth billion in only 13 years (year 1987). During the 20th century alone, the population in the world has grown from 1.65 billion to 6 billion. In October 2011, it has reached seven billion. In the last ten years the population has increased by $12 \%$, accompanied by an increase of $20 \%$ in the primary energy demand, and of $30 \%$ in electricity consumption.

According to current projections, the world population will continue to increase in the next years, and will be around eight billion by 2030, and around nine billion by 2050 .

This population explosion will present a series of interconnected challenges ranging from food and energy security, to increased terrorism and the impact of climate change.

Various predictions have been made about the future world energy consumption. The figures differ slightly according to the assumed rates of growth but all surveys indicate continued increase. Figure 2, quoted from the International Energy Agency (IEA), gives the world energy consumption in the years 1990-2035. The world's economies will continue to grow, but at varying rates. The plot sees OECD energy demand flattening through 2035 (rise of 18\%), but non-OECD demand rises by $85 \%$.

Energy security is becoming a major global concern. Fossil fuel reserves, particularly for crude oil, are confined to few areas in the world. Political, economic, and ecological factors often force volatile and high fuel prices. Simultaneously, to combat climate change, a global environmental policy which includes a major reduction in greenhouse-gas emission is required. Thus, availability of an affordable, secure and sustainable energy is necessary to preserve the living standards of developed countries and meet the right demands of developing ones.

World energy consumption in different nations occurs in patterns and is not only unequal but inequitable. Figure 3 illustrates the energy consumption per person of the 


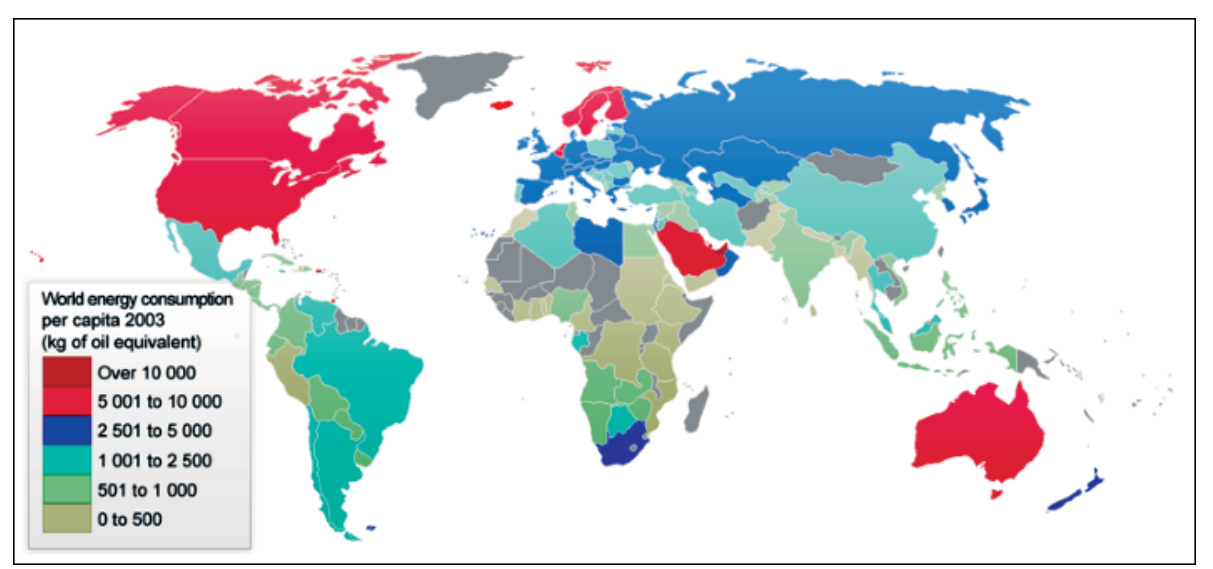

Fig. 3. - World energy consumption per capita ( $\mathrm{kg}$ of oil equivalent), in the year 2003. (Source: OECD/IEA.)

population in different countries. The citizens of USA and Canada consume about twice as much energy as the Western Europeans, who, in turn, consume energy at about twice the average value for the world. A typical person in China consumes five times less than a USA citizen, and a resident in India over ten times less. Even in such major exporting nations as Venezuela and Iran, per capita consumption of energy resources is less than one half and one quarter of the USA average, respectively. Several countries in Central Africa, Pakistan, Bangladesh, Nepal, and Peru come at the bottom place.

A striking illustration of these inequalities in the world energy consumption is shown in fig. 4, which gives the world population without access to electricity in the years 2008 and 2030: it amounted to about 1.5 billion in 2008 and will remain practically unchanged in 2030. On top of this, one should add about 1.1 billion people with erratic access to electricity. That means that around $40 \%$ of the world population has no regular access to commercial energy products in their homes.

In this scenario characterized by strikingly unequal rates of world energy consumptions it will be difficult to develop collectively rational responses to global climate threats. Furthermore, energy inequalities increase the potential for resource-based geopolitical conflicts, and foster unhealthy consumption habits throughout the developed world, while preventing entire generations of men, women, and children in the developing world from fully realizing their potential as citizens of the modern world.

The energy challenge we face is global and requires global solutions. One thing everyone agrees on is that there are no obvious solutions. Technology has a key role to play in solving the energy problems. However, no single energy carrier or option can address all outstanding issues. A broad portfolio of low-carbon sources and carriers needs to be investigated and developed as part of a general strategy to confront the growing problems faced by the whole world. Consequently, researchers must examine a broad range of options and develop many different kinds of technologies. 


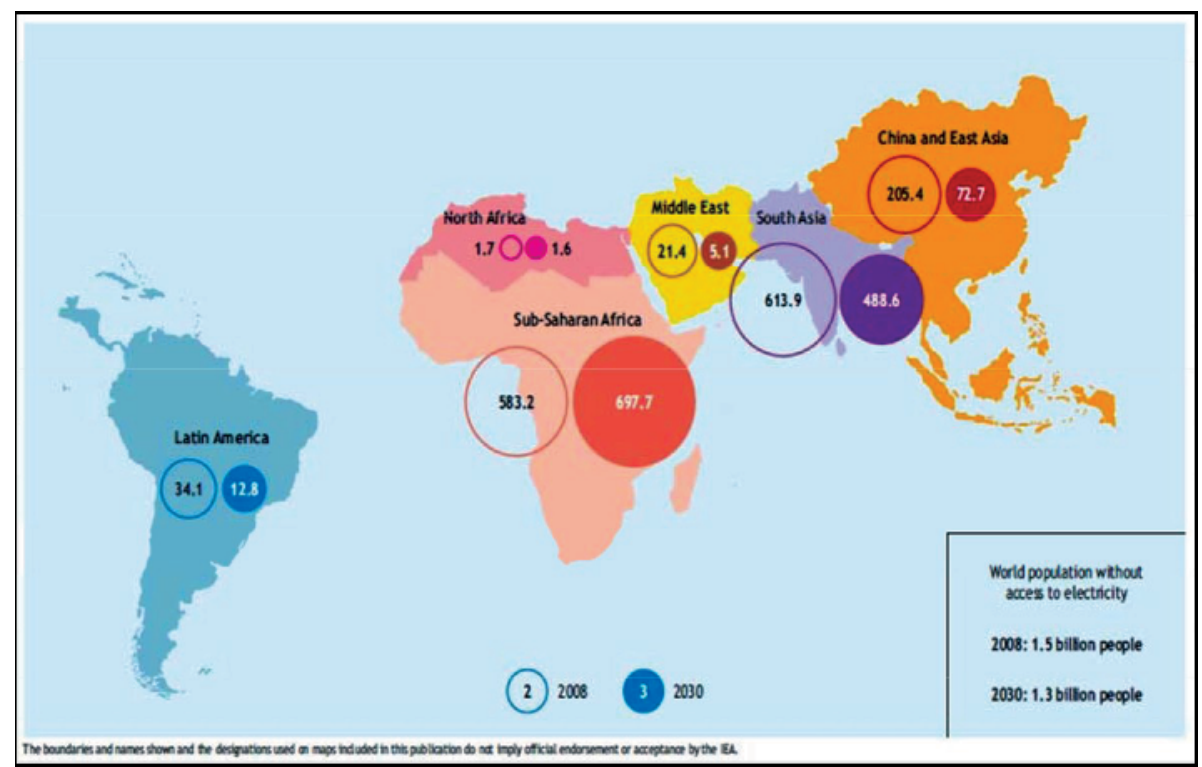

Fig. 4. - People in the world without electricity in 2008 and in 2030 (figures in the open and full circles, respectively). (Source: OECD/IEA 2009.)

Only new investments on $R \& D$ can allow to meet the growing demand for energy in a responsible, equitable, and sustainable way. This is the only way to create a sustainable energy system that adequately takes local environmental, political, social and economic conditions into account.

\section{4. - How to communicate?}

More than ever, people need some understanding of science, whether they are involved in decision-making at a national or local level, in managing industrial companies, in skilled or semi-skilled employment, in voting as private citizens or in making a wide range of personal decisions.

Science communication has, therefore, become a duty for scientists and a right for the public, a right to know and a right to engage. But the duty is not always welcome and the rights are not always enthusiastically exercised. Then, communicating science in ways that are useful and meaningful for both science and society remains a challenge.

The aim of science communication is to transmit information to selected audiences in the clearest possible manner, in such a way to provide those audiences with information that is useful to them. Today, communication of science is no longer simple dissemination of the knowledge produced by scientists, who are the source of the flow of information, and to some degree the censor as well. In this framework [5] the objective of communication is of informing the public rather than engaging; the choice of what knowledge ought to be given is based on the presumed cultural and cognitive gaps in the public, rather than 
on their questions, interests and skills. Communicators who think only of the message to convey and not of the audience are likely to fail.

Today communicating science is a more sophisticated process in which psychological, and emotional concerns play an important part [6]. To be effective with any audience, science communication must be an interactive process. The solution is not in more information about science but in more effective communication and dialogue. Rather than informing audiences, one must engage them.

The starting point of a good communication is the knowledge of the matter by the audience, which is the end user of the information. Clearly, each audience is different, both in terms of its capacity to understand the information and the use it makes of the knowledge. Communicators must immediately make some assumptions about the people they are addressing, their interests, beliefs and background and tailor the communication expressly for the audience. Failure to observe this simple rule can create a distance in which the message risks getting lost.

To be effective with any audience, science communication must be an interactive process. Before talking, one must listen; to make oneself understood, one must first understand. Instead of asking only "What do people need to know?", one should ask: "What do people think they need to know?", "What will be the effect on people of what I want to say?", "What do they know or think they already know?".

Science communication should be one of the primary duties of scientists and should not be solely assigned to science communicators and journalists, as it is often done now. A close collaboration of scientists and science communicators is necessary for an effective and efficient popularization of science. On the one hand, scientists should take a look at what underlies the work of professional communicators, like journalists, who understand how to address the public at large, and learn to use their skills for the benefit of science. On the other hand, attending seminars, summer schools, direct participation in research should be the rule for science communicators, in order to obtain a free and informal contact of minds between science reporters and scientists on an equal level, instead of an undirected flow of undigested information.

While the energy challenge is global, and fields of R\&D are interdisciplinary and closely interrelated, energy communication is almost local. Every laboratory/university, every discipline, and every country communicates for its own. To succeed, we must all succeed. The time when one country, one region or one discipline can succeed at the expense of another is over.

All countries in the world are becoming increasingly interdependent and, therefore, aim at international projects and agreements. As national energy decisions on energy supply and infrastructures have impact on other countries one must also aim at an international model of energy communication that fosters and facilitates sharing of resources, images, news and other information for news stories, articles, presentations, reports and papers which help to inform the public about the current status of initiatives.

An example of this is the Action Plan adopted by the European Commission to achieve a $20 \%$ reduction in energy consumption by 2020 [7]. The plan includes measures to improve the energy performance of products, buildings and services, to improve the 


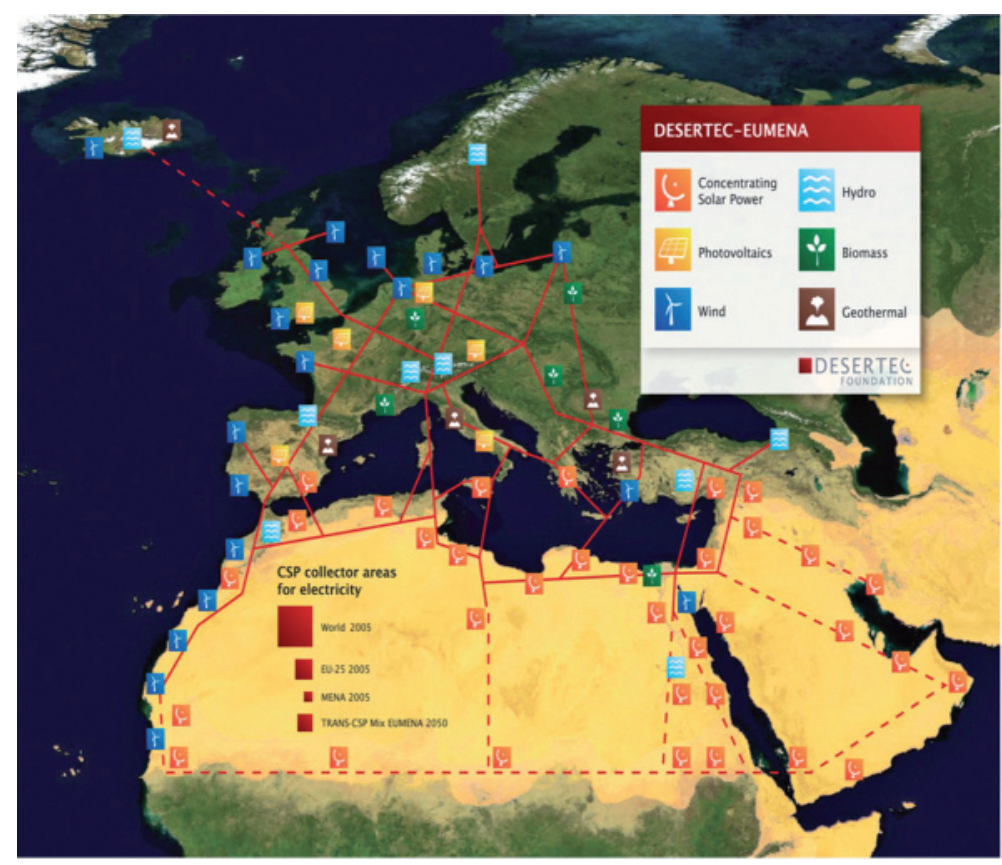

Fig. 5. - Sketch of possible infrastructure for a sustainable supply of power to Europe, the Middle East and North Africa (EU-MENA). (Source: DeserTeC Foundation - http://www desertec. org/.)

yield of energy production and distribution, to reduce the impact of transport on energy consumption, to facilitate financing and investments in the sector, to encourage and consolidate rational energy consumption behaviour and to step up international actions on energy efficiency. The purpose of this Action Plan is to mobilise the general public, policy-makers and market actors, and to transform the internal energy market in a way that provides EU citizens with the most energy-efficient infrastructure, products, and energy systems in the world. As consumers' decisions will determine the success of the results, the Commission has wisely planned a number of educational measures to raise public awareness of the importance of energy efficiency, including education and training programmes on energy and climate change issues.

Another example is the DESERTEC project [8], the mega renewable-energy project developed by a network of politicians, scientists and economists from around the Mediterranean. The project (see fig. 5) aims to setup a massive network of solar power plants, photovoltaic systems and wind parks stretching across the desert regions in Middle East and Northern Africa. The generated electricity would be transmitted to European and African countries by a super grid of high-voltage direct current cables. It would provide a considerable part of the electricity demand of the Middle East and North Africa countries and furthermore provide continental Europe with $15 \%$ of its electricity needs. 
It is an ambitious project that promises to revolutionize the way we produce energy. To succeed, all interested countries, industries, research organizations must collaborate in an effective and efficient way. Besides the solution of many challenging technical problems, for the realization of the project it is also needed a concerted and coherent international communication campaign to inform the interested governments and citizens that those plants, over their lifetimes, will be a clean, safe and stable source of power, competitive with electricity generated from clean coal, oil or natural gas with their soaring or fluctuating fuel costs. One must convince governments of the need to cooperate for the development of the unlimited renewable energy resources that are available, instead of increasingly fighting for access to and exploitation of the remaining limited fossil energy resources.

Along this line and very timely, the European Physical Society (EPS) has recently established an Energy Group (EG) [9] to provide a forum for European scientists interested in any aspect of physics research and development related to the science of energy and technologies for the supply, distribution, transformation and use of energy in society.

In its activities the EG pays particular attention to aspects of sustainability, environmental acceptability and climate compatibility in a European and global perspective. It organizes conferences and workshops, undertakes through ad hoc groups analyses of (physics based) energy issues and formulates recommendations where adequate. It also supports education and training and the promotion of public understanding of energy issues.

Once more, scientists are at the forefront of the international understanding and collaboration.

\section{5. - Conclusions}

Science and technology have not only changed the way we live our lives, but they are at the heart of every major challenge we now face. An educated audience can better appreciate the scientific work, and take far more from it than if it is ignored. Energy and scientific communication have, therefore, become a real duty and a big challenge for scientists. They are particularly important today, when the world is confronted with a number of immediate, urgent problems.

For an effective communication it is important to establish an open dialogue with the audience, and a close collaboration among scientists and science communicators. An international collaboration in energy communication is appropriate to better support international and interdisciplinary research and projects.

\section{REFERENCES}

[1] Muller R. A., Physics for Future Presidents: The Science Behind the Headlines (W.W. Norton \& Company) 2008.

[2] The sentence is taken from: Feynman R. P., The Meaning of it All (Penguin) 1999.

[3] For more information visit http://public.web.cern.ch/public/. 
[4] http://www.worldometers.info/world-population.

[5] This communication model emerged under the title "Public understanding of science" after the influential report of the Royal Society of London of 1985. The report can be downloaded from http://royalsociety.org/Public-Understanding-of-Science/.

[6] An exhaustive treatment of public science communication can be found in the book by Carrada F., Communicating Science. A Scientific Survival Kit (European Communities) 2006.

[7] http://europa.eu/legislation_summaries/energy/energy_efficiency/127064_en.htm.

[8] http://www.desertec.org.

[9] More information can be found in the site http://energygroup.epsdivisions.org/. 